\title{
IL-12 in Conjunction with Dendritic Cells Enhances Antiviral CD8+ CTL Responses In Vitro
}

\author{
Nina Bhardwaj, ${ }^{\star \ddagger}$ Robert A. Seder, ${ }^{\S}$ Anita Reddy, ${ }^{\star}$ and Mary V. Feldman* \\ *The Rockefeller University, New York 10021; the ${ }^{\ddagger}$ Hospital for Special Surgery, New York 10021; and the ${ }^{\S}$ National Institutes of Health, \\ Bethesda, Maryland 20892
}

\begin{abstract}
CD8 + cytolytic T lymphocytes (CTLs) are important mediators for resistance to infections and malignant diseases. IL-12 enhances proliferative and cytolytic responses by killer cells, but its function in the generation of human antiviral $\mathrm{CD} 8+\mathrm{T}$ cell responses has not been defined. We therefore evaluated the role of IL-12 in the generation of CTLs to influenza-infected dendritic cells. IL-12 was not detectable in supernatants of infected-dendritic cells, or during CTL generation. Furthermore, anti-IL-12 antibody did not block CTL generation. However, exogenous IL-12 (30$300 \mathrm{pg} / \mathrm{ml}$ ) enhanced CD8 $+\mathrm{T}$ cell proliferative and cytolytic responses. The effect was greatest in individuals with weak reactivity to influenza virus or at antigen-presenting cell (APC): $T$ cell ratios of 1:100 or less. IL-12 augmented interferon- $\gamma$ production during CTL generation. The CTL enhancing effects of the cytokine, however, could not be blocked by neutralizing anti-interferon- $\gamma$ antibody. Together with IL-12, antigen-pulsed dendritic cells may be a useful approach for boosting CTL responses against infectious agents and malignancies. (J. Clin. Invest. 1996. 98: 715-722.) Key words: dendritic cells - cytolytic T cells • CD8 $+\mathrm{T}$ cells $\bullet$ interleukin $12 \cdot$ vaccines
\end{abstract}

\section{Introduction}

IL-12 is a heterodimeric cytokine with multiple immunoregulatory activities $(1,2)$. A critical component of the host's innate immune response to infection, IL-12 is produced early during the inflammatory response by macrophages. It enhances natural killer $(\mathrm{NK})^{1}$ cell cytoxicity severalfold and rapidly induces the production of IFN $\gamma$, the latter enhancing the antimicrobial activity of phagocytic cells (3-6). IL-12 is also a crucial participant in the development of acquired immune responses. It induces the differentiation of Th1 cells through its ability to prime naive Th0 cells for high IFN $\gamma$ production $(7,8)$. Furthermore, it is a potent growth factor for CD8+ T cells (7) and enhances cytolytic responses to alloantigens (9-11) and in antiCD3 redirected assays (12).

Here, we have evaluated the role of IL-12 in generating cy-

Address correspondence to Nina Bhardwaj, The Rockefeller University, 1230 York Avenue, New York, NY 10021. Phone: 212-327-8332; FAX: 212-327-8875; E-mail: bhardwn@rockvax.rockefeller.edu

Received for publication 18 March 1996 and accepted in revised form 23 May 1996.

1. Abbreviations used in this paper: APC, antigen-presenting cell; CTL, cytolytic T lymphocyte; E:T, effector:target; NK, natural killer.

The Journal of Clinical Investigation

Volume 98, Number 3, August 1996, 715-722 tolytic $\mathrm{T}$ lymphocyte (CTL) responses to influenza virus, which continues to be a source of significant morbidity and mortality in humans. We have previously shown that potent human CD8+ CTL responses to live or nonreplicating heatinactivated influenza virus can be generated from freshly isolated blood $\mathrm{T}$ cells, provided dendritic cells are the antigenpresenting cells (APCs) $(13,14)$. The response is independent of CD4+ T cells or exogenous cytokines. Small numbers of dendritic cells suffice, whereas other APCs (macrophages, B cells) are inactive in this regard. Dendritic cells effect the development of Th1 cells from Th0 cells by the production of IL-12 (15), suggesting that IL-12 is a key component by which these APCs induce T cell-mediated immune responses.

Using the influenza virus system as a model, we show that dendritic cells induce potent CTL responses without producing significant levels of IL-12 endogenously. However, the exogenous application of IL-12 significantly enhances these responses, especially when the baseline CTL response of the donor is poor, or if the number of dendritic cells is limiting. Based on these findings we suggest that IL-12 may be a useful adjuvant for the induction of CTL responses, especially when delivered concomitantly with dendritic cells.

\section{Methods}

\section{Culture medium}

RPMI-1640 (Gibco Laboratories, Grand Island, NY) supplemented with $20 \mathrm{ug} / \mathrm{ml}$ gentamicin, $5 \%$ human serum, and $10 \mathrm{mM}$ Hepes buffer.

\section{Blood mononuclear cells}

$T$ cells. PBMCs were isolated from buffy coats by density gradient centrifugation over Ficoll Hypaque. T cell-enriched and T cell-depleted (ER-) fractions were prepared by sheep erythrocyte rosetting. T cells were further purified by removal of monocytes, NK cells, and MHC class II+ cells by panning with antibodies to CD11b, CD16, and DR, as described (13). T cell subsets (CD4+ and CD8+) were negatively selected by incubation with Leu 2 or Leu $3 \mathrm{mAbs}$, followed by panning onto plastic plates coated with goat anti-mouse $\operatorname{IgG}(13)$.

Antigen presenting cells. Monocytes were obtained from ERcells by adherence to plastic for $90 \mathrm{~min}$. The monocytes were dislodged and used as targets in ${ }^{51} \mathrm{Cr}$ release assays (see below). Nonadherent ER- cells were depleted of residual monocytes by panning on gamma globulin-coated dishes. The remaining cells (primarily B cells and dendritic cells) were adequately enriched for dendritic cells to induce strong CTL responses (13). Since B cells pulsed with influenza virus do not elicit CTL responses, in part because the $B$ cell is not infected with influenza virus (13), we used mixtures of B cells and dendritic cells as APCs in some experiments. Highly purified dendritic cells $(>75 \%)$ were obtained as low density cells by metrizamide gradient centrifugation, as previously described (13).

\section{Virus preparation}

Influenza A virus (PR8, Puerto Rico/8/34, source: allantoic fluid; Spafas Inc., Storrs, CT) was either live, or inactivated at $56^{\circ} \mathrm{C}$ for 30 min in a water bath. Nonreplicating, heat-inactivated virus, which re- 
tains hemolytic and hemagglutinating activity, is as potent as live virus in inducing CD8+ antiinfluenza CTL responses (14).

\section{Cytokines}

IL-12 (specific activity $5 \times 10^{6} \mathrm{U} / \mathrm{mg}$ ) was generously provided by Dr. Stanley Wolf (Immunology Department, Genetics Institute, Inc). Recombinant human IL-4, IL-15, and IL-7 were purchased from R \& D Systems Inc. (Minneapolis, MN). ELISA kits measuring IL-12, IL-2, IL-6, TNF $\alpha$, and IFN $\gamma$ were purchased from R \& D Systems, Inc.

\section{Neutralizing antibodies}

Polyclonal goat anti-human IL-12, IL-2R (alpha chain, CD25), and IFN $\gamma$ antibodies were purchased from R \& D Systems, Inc. The hybridoma producing neutralizing anti-human IL-12 monoclonal antibody (C8.6) was kindly provided by Dr. G. Trinchieri of the Wistar Institute (Philadelphia, PA).

\section{Induction of CTL responses}

Dendritic cells were infected with 1,000 HAU/ml (moi of 2-4) of different forms of live or heat-inactivated influenza virus for $1 \mathrm{~h}$ at $37^{\circ} \mathrm{C}$ in serum free medium, washed extensively, and added to bulk cultures of purified syngeneic $\mathrm{T}$ cells in 24-well or 48-well plastic dishes (Falcon Labware, Lincoln Park, NJ). After $7 \mathrm{~d}$, the cells were harvested and distributed in varying numbers in $100-\mu \mathrm{l}$ vol to $96-$ well microtiter plates. CTL activity was measured using a standard ${ }^{51} \mathrm{Cr}$-release assay with infected or uninfected macrophages, as previously described (13). Effector:target (E:T) ratios were 30:1-40:1. In brief, macrophages were brought to $10^{7} / \mathrm{ml}$ in serum-free medium, and infected with $1,000 \mathrm{HAU} / \mathrm{ml}$ of influenza virus. The cells were simultaneously labeled with ${ }^{51} \mathrm{Cr}$ by the addition of $400 \mu \mathrm{Ci}$ of $\mathrm{Na}^{51} \mathrm{CrO}_{4}(1$ $\mathrm{mCi} / \mathrm{ml}$, sterile stock; New England Nuclear, Boston, MA) per milliliter. The targets were then washed four times, resuspended to $2 \times 10^{5} /$ $\mathrm{ml}$, and aliquoted in $50 \mu \mathrm{l} \mathrm{vol}$ to $96-w e l l$ round bottom dishes containing effector cells. Percent specific ${ }^{51} \mathrm{Cr}$ release was calculated from the following formula: $100 \times([$ release by CTL - spontaneous release] $/$ [total release - spontaneous release]). Spontaneous release was generally $15 \%$ of the total release.

\section{Proliferation assays}

$2 \times 10^{5}$ bulk or CD8 $+\mathrm{T}$ cells were plated in 96-well flat bottomed plates (Costar, Cambridge, MA) in the presence or absence of varying concentrations of cytokines. APCs were partially purified dendritic cells (T:APC ratio of 5:1) or purified dendritic cells (T:APC ratio of 30:1). APCs were infected with influenza virus as described above. Uninfected APCs served as controls. Proliferation was determined on days 5-6 with the addition of $4 \mu \mathrm{Ci} / \mathrm{ml}$ of ${ }^{3} \mathrm{H}-\mathrm{TdR}$ for $12-16 \mathrm{~h}$ to triplicate microwells (mean $\mathrm{cpm}$ ).

\section{Results}

IL-12 is not produced in dendritic cell-dependent CTL responses. Potent antiinfluenza CTL responses are induced from resting CD8+ T cells when dendritic cells are the APCs (13). Dendritic cells can produce IL-12 $(15,16)$ and direct the development of Th1 cells from CD4+ T cells (15). However, it is not known whether IL-12 is synthesized after infection with virus and during contact with CD8+ T cells. Using a sensitive ELISA system, we found that dendritic cells infected with live replicating influenza virus produced little to no IL-12 p70 heterodimer (range of 4-10 $\mathrm{pg} / \mathrm{ml}$ in four separate experiments). Furthermore, significant levels of IL-12 were not detectable in T cell-dendritic cell culture supernatants over the 7-d period during which CD8+ CTLs normally develop $(<15 \mathrm{pg} / \mathrm{ml})$. In contrast the cytokines IL-2, TNF $\alpha$, IFN $\gamma$ and IL-6 were detectable by ELISA (data not shown). Several other stimuli including LPS (reported to induce IL-12 mRNA in murine splenic dendritic cells, [17]), superantigens (staphylococcal enterotoxins), or addition of allogeneic $\mathrm{T}$ cells also failed to elicit high levels of IL-12 by dendritic cells.

In the CTL cultures, dendritic cells were added at 1 cell per $30 \mathrm{~T}$ cells. We considered the possibility that very low levels of IL-12 were produced in the supernatants. Neutralizing antiIL-12 antibody was therefore added to the culture system. CTL responses were not blocked by anti-IL-12 antibody (5-25 $\mu \mathrm{g} / \mathrm{ml}$ [Fig. 1] and data not shown) but were significantly suppressed by the addition of anti-IL-2 R antibody ( $\alpha$ chain specific). IFN $\gamma$ production was also unaffected by the addition of anti-IL-12 to the dendritic cell-T cell cultures. This suggests that endogenous IL-2, rather than IL-12, was responsible for IFN $\gamma$ production. Indeed, IFN $\gamma$ levels were markedly diminished by the addition of anti-IL-2 $\mathrm{R} \alpha$ antibody (Fig. 1). Thus our data suggest that dendritic cells do not produce biologically significant levels of IL-12 after virus infection, and that IL-12 is not produced during the development of potent antiviral CTLs. The antiinfluenza CTLs that are generated in bulk $\mathrm{T}$ cell cultures by virus-infected dendritic cells are CD8+ (13). However, there is a substantial number of CD4+ T cells presumably responding to influenza antigens in a class II restricted fashion. Even their presence, however, was insufficient to elicit IL-12 from influenza infected dendritic cells.

IL-12 enhances $T$ cell proliferative responses to influenzavirus infected dendritic cells. IL-12 stimulates the proliferation of activated $\mathrm{T}$ and NK cells but causes minimal proliferation of resting peripheral blood mononuclear cells (7). We evaluated the effects of IL-12 on enhancing T cell proliferative responses to influenza virus-infected dendritic cells. Marked increases in proliferative responses were noted with the addition of IL-12 at low doses (Fig. 2). IL-12 is known to enhance proliferative responses to mitogen-activated T cells in the picomolar range (7). This was true for both bulk T cells (Fig. $2 A$ ),

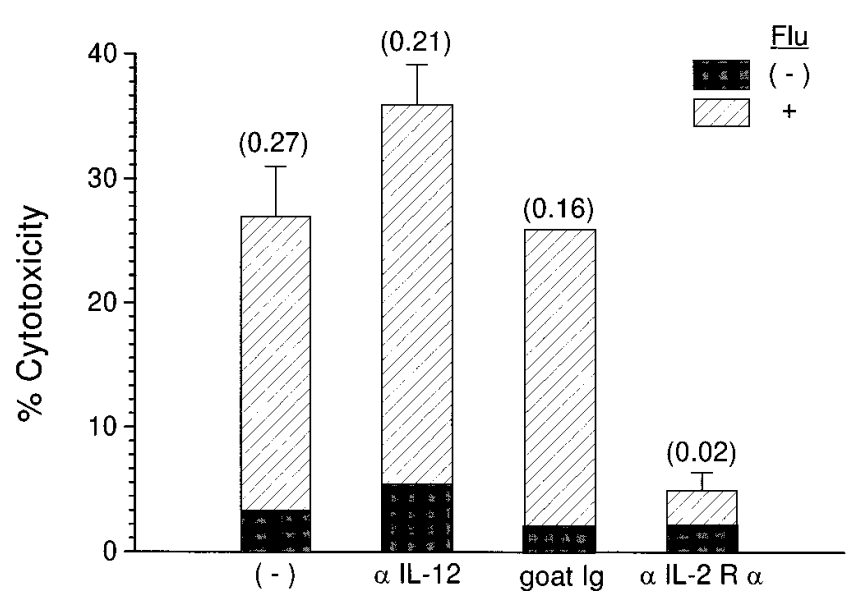

Figure 1. Antiviral CTL and IFN $\gamma$ responses that are induced by dendritic cells are blocked by anti-IL-2 but not anti-IL-12 antibodies. Bulk T cells were cocultured with uninfected or influenza infected dendritic cells (T:DC ratio 30:1) in the presence of $5 \mu \mathrm{g} / \mathrm{ml}$ of goat anti-IL-12 ab and anti-IL-2R alpha chain ab, or goat IgG. After $7 \mathrm{~d}$ the effector cells were tested for cytolytic activity of influenza infected syngeneic macrophage targets in a $\mathrm{Cr}$ release assay. E:T ratio was 30:1. Lysis of uninfected macrophage targets was $<5 \%$ (data not shown). Similar results were obtained in three other experiments. The numbers in parentheses refer to the concentrations of IFN $\gamma$ (ng/ $\mathrm{ml}$ ) in the supernatants on the third day of culture. 

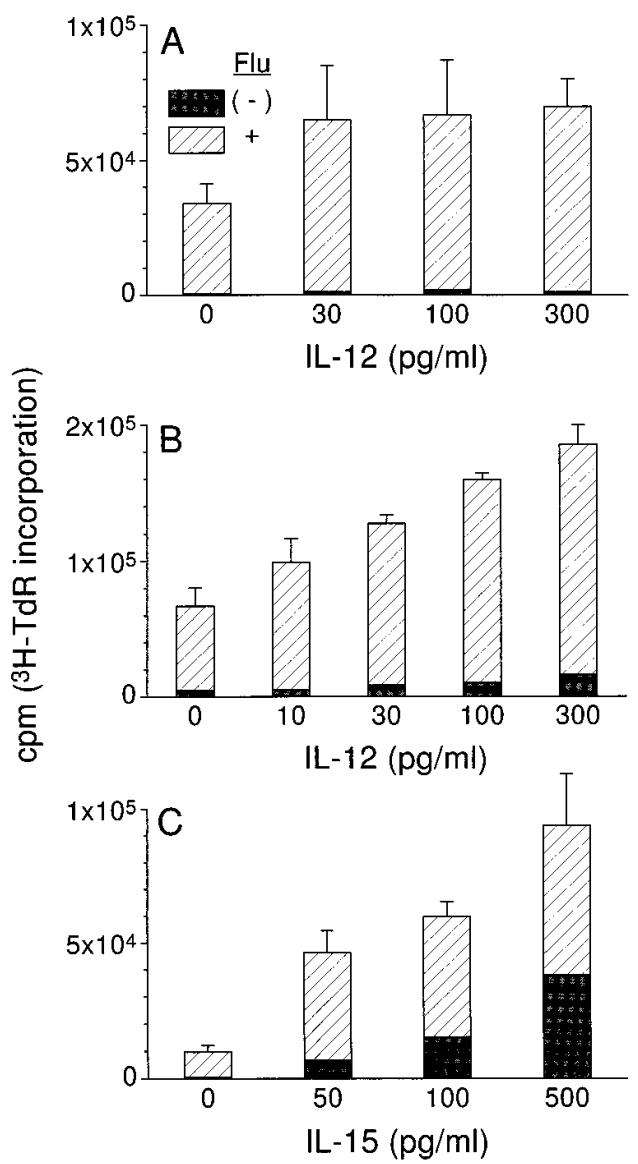

Figure 2. IL-12 enhances T cell proliferative responses to influenza virus-infected dendritic cells. Bulk T cells $(A),(C)$ or CD8+ T cells $(B)$, were cultured with virus-infected or uninfected APCs for $5 \mathrm{~d}$. IL-12 ( $A$ and $B)$ and IL-15 $(C)$ were added in graded doses. Black portions of the bars represent the proliferative response to uninfected APCs while the hatched portion represent the responses to influenzainfected APCs. Proliferation was determined by the addition of ${ }^{3} \mathrm{H}-\mathrm{TdR}$ for $16 \mathrm{~h}$ on day 5 . Results are means of triplicates. The data are representative of two experiments. as well as for highly purifed CD8+ $\mathrm{T}$ cells (Fig. 2 B). Background responses were minimal. $\mathrm{T}$ cell yields were increased up to twofold (data not shown). We also evaluated IL-15, a cytokine which shares many of the properties of IL-2 (18), and enhances CD4+ T cell-dependent responses to antigen (19). In contrast to IL-12, IL-15 produced dramatic background responses in bulk $\mathrm{T}$ cell populations (Fig. $2 \mathrm{C}$ ). Antigen specific $\mathrm{T}$ cell proliferative responses were still evident, however. IL-15 can induce some proliferation in bulk populations of human blood mononuclear cells (19). When IL-15 was added to purified CD8+ T cells, the responses generated to uninfected vs virus-infected dendritic cells was similar even with low doses, e.g., $50 \mathrm{pg} / \mathrm{ml}$ (data not shown).

IL-12 enhances weak antiviral cytolytic $T$ cell responses. While dendritic cells induce strong CD8+ CTL responses to influenza virus, macrophages are weak or inactive. This may be due to apoptosis, observed 12-16 h after infection of macrophages with virus (20). However, macrophages are useful as target cells in short term CTL assays because $>70 \%$ get infected. B cells are poor stimulators of the T cell response to the virus, probably because they are infected poorly with influenza (13). As a result it is convenient for eliciting CTL responses to select macrophages as CTL targets, and to use T and macrophage-depleted blood populations as partially enriched sources of dendritic cells. The latter generally contain about $3-5 \%$ dendritic cells and are highly effective at inducing CD8+ CTL responses (13).

IL-12 (100 pg/ml) enhanced the cytolytic activity of bulk T cells towards influenza-infected, macrophage target cells (Fig. 3). Two situations were identified where IL-12 was most effective. When low doses of APCs were used (T:APC ratio $=30: 1$, Fig. 3A or T:dendritic cell ratio $=100: 1$, Fig. 3 B), IL-12 restored cytolytic activity to levels seen at higher doses of APCs. IL-12 was also effective when the blood donors had weak baseline antiinfluenza CTL responses (Fig. $3 \mathrm{~B}$ ). The enhancing effects of IL-12 were also evident with highly purified $\mathrm{CD} 8+\mathrm{T}$ cells that were stimulated with influenza-infected dendritic cells (Fig. 4). We confirmed that the responding cells in the preparation were primarily $\mathrm{CD} 8+$, by staining with monoclonal antibodies at the end of the 7-d culture period (data not shown).

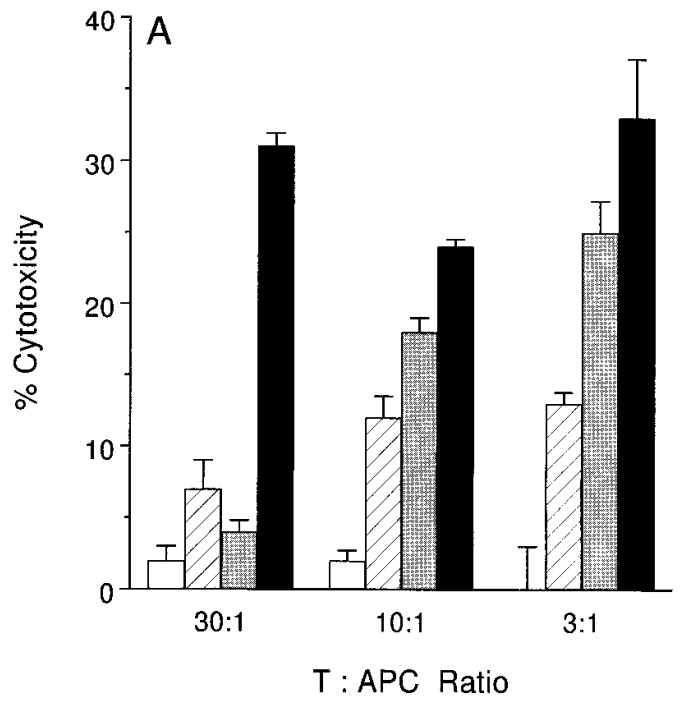

T : APC Ratio

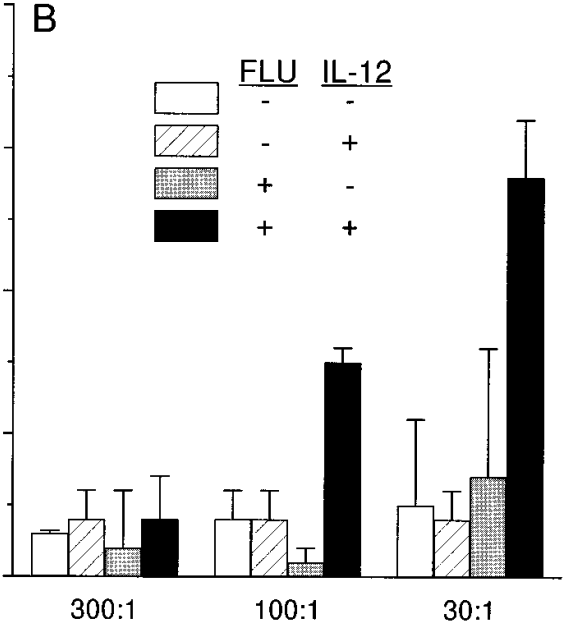

T : DC Ratio
Figure 3. IL-12 enhances antiinfluenza virus CTL responses induced by dendritic cells. Partially enriched dendritic cells or "APCs" $(A)$, or purified dendritic cells $(B)$, were uninfected or infected with influenza virus and added at various ratios to bulk T cells. IL-12 was added at $100 \mathrm{pg} / \mathrm{ml}$. Lytic activity was determined after $7 \mathrm{~d}$ on syngeneic macrophage-infected targets $($ E:T ratio $=40: 1)$. Lysis of uninfected targets was $<5 \%$ (data not shown). 


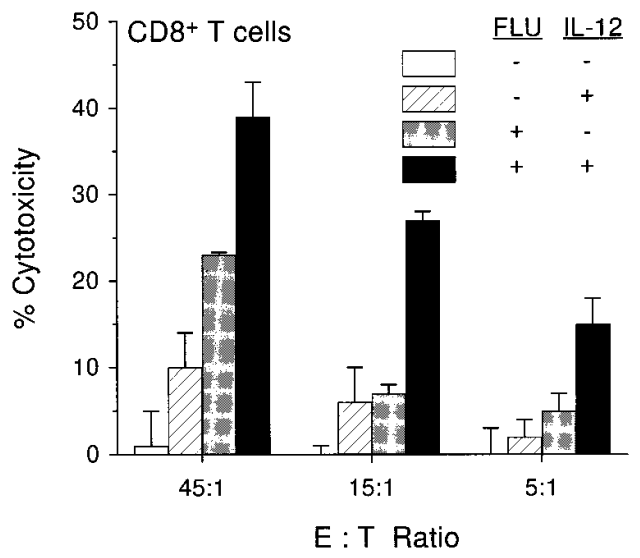

Figure 4. IL-12 enhances cytolytic $\mathrm{T}$ cell responses from purified CD8 + T cells. CD8 + T cells were cultured with uninfected or influenza virus-infected APCs (partially enriched dendritic cells) at T:APC ratio of 50:1 in the presence or absence of IL-12 (100 pg/ml).
In summary, IL-12 appears to be most effective in enhancing CD8+ CTL responses when APC numbers are limiting or the CTL response of the donor is weak to begin with.

$I F N \gamma$ is not responsible for the IL-12-induced enhancement of CTL responses. IL-12 has a major role in facilitating the production of IFN $\gamma$ by peripheral blood lymphocytes (reviewed in [1]). IL-12 enhanced both antiviral cytolytic responses and IFN $\gamma$ production in a dose-dependent manner (Fig. $5 \mathrm{~A}$ ). The highest responses were observed at doses of 100-300 $\mathrm{pg} / \mathrm{ml}$, similar to that seen in the $\mathrm{T}$ cell proliferation assays (Fig. 2). Similar results were obtained when (a) CD8+ $\mathrm{T}$ cells were used (data not shown), or $(b)$ heat inactivated,

After $7 \mathrm{~d}$, effector cells were harvested and lytic activity was determined on syngeneic macrophage-infected targets at various E:T ratios. Lysis of uninfected targets was $<5 \%$ at all E:T ratios used (data not shown). This result is typical of experiments with donors exhibiting CD8+ CTL responses of 20-30\% without IL- 12 .

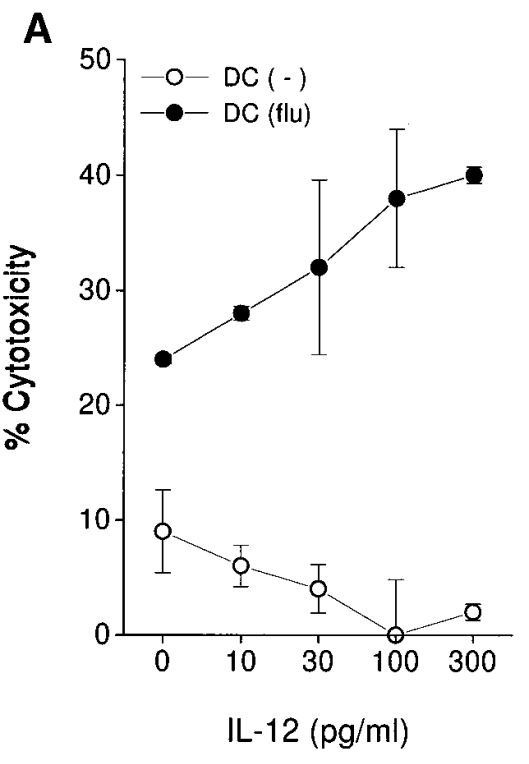

B

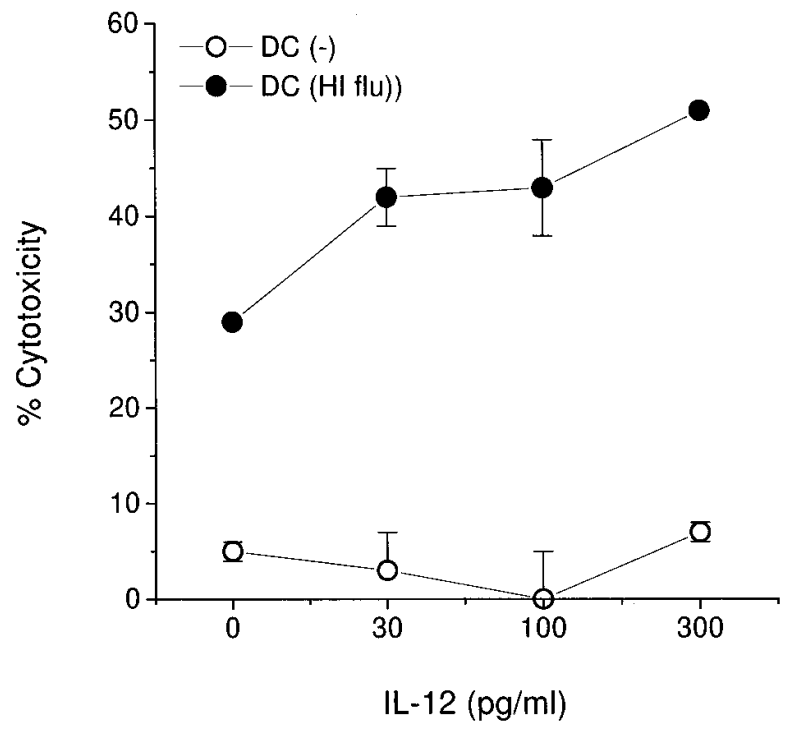

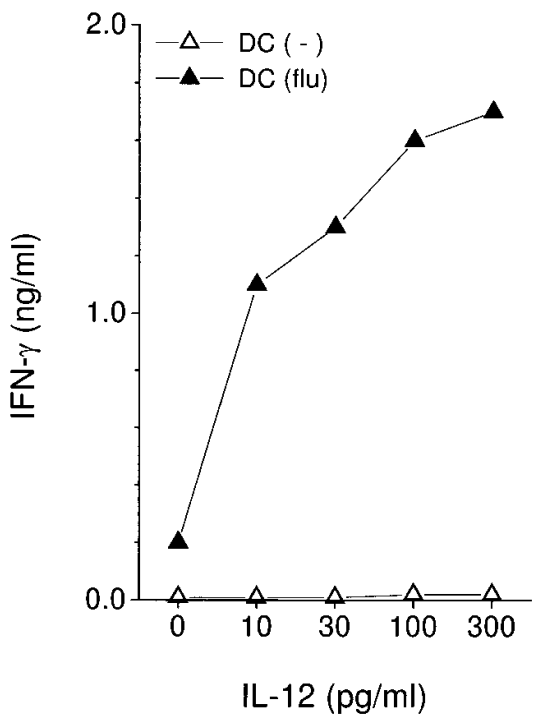

Figure 5. Exogenous IL-12 enhances dendritic cell-dependent CTL responses and IFN $\gamma$ production in a dose-dependent fashion. (A) Bulk T cells were cultured with influenza-infected or uninfected dendritic cells $(\mathrm{T}: \mathrm{DC}=50: 1)$ in the presence or absence of IL-12 (10$300 \mathrm{pg} / \mathrm{ml})$. After $7 \mathrm{~d}$ effector T cells were assessed for lytic responses on infected syngeneic macrophages $(l e f t)$. Supernatants were collected from the cultures on day 3 and evaluated for IFN $\gamma$ production $(r i g h t) .(B)$ Bulk T cells were cultured with uninfected dendritic cells or cells infected with heat inactivated influenza virus $(\mathrm{T}: \mathrm{DC}=$ $50: 1)$ in the presence or absence of IL-12 (10-300 pg/ml). Effector cytolytic activity was measured as described after $7 \mathrm{~d}$. 
Table I. Anti-IFN $\gamma$ does not Block the CTL-enhancing Function of IL-12

\begin{tabular}{llcc}
\hline & & \multicolumn{2}{c}{ Percentage specific lysis of targets } \\
\cline { 3 - 4 } HI-FLU & \multicolumn{1}{c}{ Treatment } & MO [-] & MO [+] \\
\hline- & goat Ig & 0 & 5 \\
- & anti-IFN $\gamma$ & 0 & 8 \\
- & IL-12 & 0 & 5 \\
- & IL-12 + goat Ig & 0 & 5 \\
- & IL-12 + anti-IFN $\gamma$ & 0 & 3 \\
+ & goat Ig & 0 & 17 \\
+ & anti-IFN $\gamma$ & 0 & 17 \\
+ & IL-12 & 2 & 36 \\
+ & IL-12 + goat Ig & 3 & 45 \\
+ & IL-12 + anti-IFN $\gamma$ & 3 & 34 \\
\hline
\end{tabular}

Highly purified CD8 $+\mathrm{T}$ cells were cultured with uninfected dendritic cells or dendritic cells infected with heat-activated influenza virus (HI-FLU) in the presence or absence of interleukin $12(300 \mathrm{pg} / \mathrm{ml})$. The T:APC ratio was 50:1. Neutralizing goat anti-IFN $\gamma$ or control goat IgG were added at a final concentration of $25 \mu \mathrm{g} / \mathrm{ml}$ on the first and fourth days of culture. Antiviral cytolytic activity was assessed on syngeneic uninfected, MO [-], or virus-infected macrophage targets, MO $[+]$, after 7 days. The data are representative of three experiments.

replication deficient virus was used (Fig. 5 B). Even at low doses $(10 \mathrm{pg} / \mathrm{ml})$, there was greater than fivefold increase in the quantity of IFN $\gamma$ produced. This sensitivity to IL-12 has been described in other culture systems $(1,5,6)$.

We considered the possibility that IFN $\gamma$ production induced by IL-12 was mediating the induction of CD8+ CTLs by virus-infected dendritic cells. Endogenous IL-12 production is critical to the generation of NK cell and $\mathrm{T}$ cell responses through the production of IFN $\gamma$, best demonstrated in models of bacterial and parasitic infections (reviewed in [1]). We added large doses of neutralizing anti-IFN $\gamma$ antibody to cocultures of $\mathrm{T}$ cells and virus-infected dendritic cells in the presence of IL-12. As seen in Table I, the antibody did not block the induction of cytolytic activity in highly purified CD8+ T cell populations. We confirmed that significant amounts of IFN $\gamma$ were being synthesized in the culture medium in response to IL-12 (up to $2.7 \mathrm{ng} / \mathrm{ml}$ ). Since our cultures were extensively depleted of NK cells, it is unlikely that they were the source of IFN $\gamma$ production (see below). We verified that the major responding cells in the cultures after $7 \mathrm{~d}$ were CD8+ T cells and not NK cells by $\mathrm{FACS}^{\circledR}$ analysis.

We determined that IL-12 was responsible for the majority of IFN $\gamma$ production by CD8+ CTLs. Anti-IL-12 neutralizing antibody blocked the induction of IFN $\gamma$ release induced by IL12 , as well as the enhanced CTL responses. Anti-IL-2 R $\alpha$ only partially reduced the IFN $\gamma$ release and CTL responses induced by IL-12 (by $\sim 40 \%$, data not shown), indicating that the majority of IFN $\gamma$ produced is due to IL-12.

Comparison of a panel of cytokines on the enhancement of antiviral CTL responses. IL-12 was compared with a panel of cytokines that are also known to promote CD8+ CTL responses. IL-12 was the most potent enhancer of antigendependent CTLs (Fig. 6, $A$ and $B$ ). IL-7, a growth factor implicated in the development of CD8+ CTLs (21), appeared to be considerably less effective even when added at $1 \mathrm{ng} / \mathrm{ml}$. Interestingly, IL-4, a key cytokine for the induction of Th2 re-
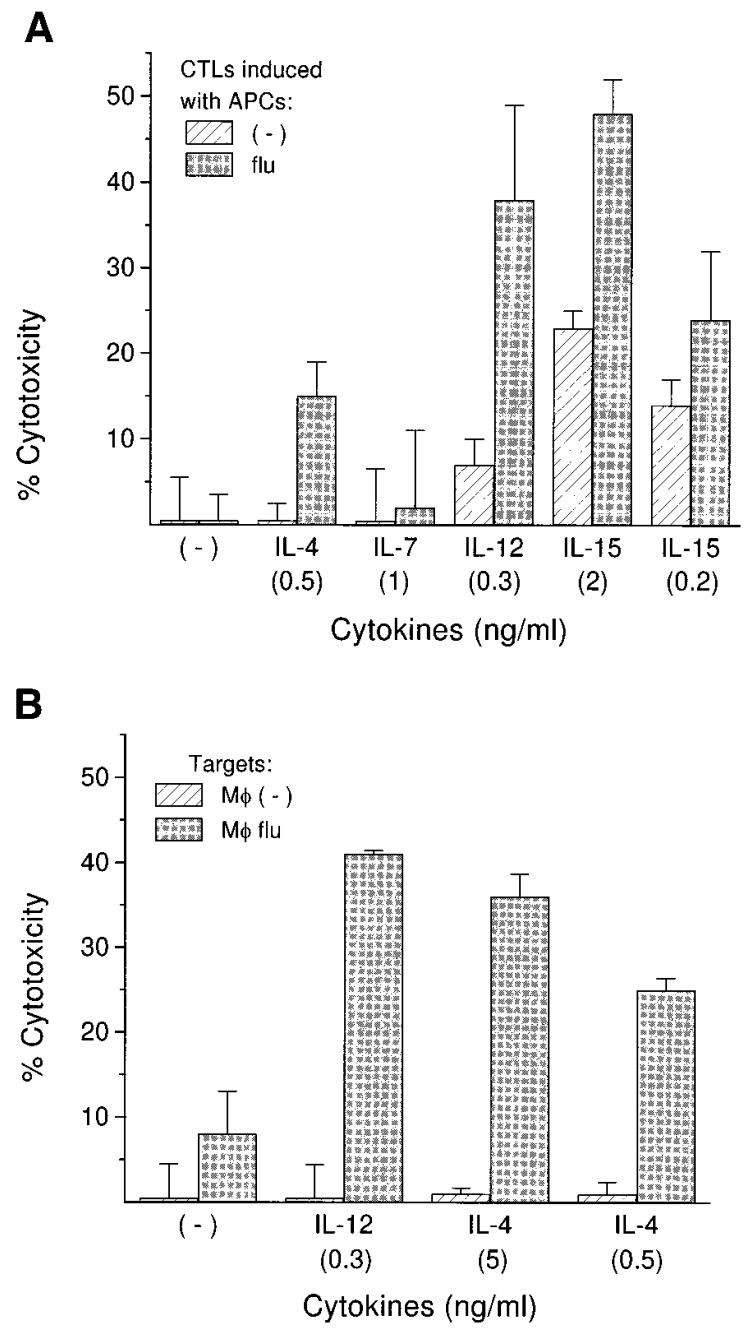

Figure 6. Both IL-12 and IL-4 can selectively enhance virus-specific CTL responses to influenza virus-infected dendritic cells. $(A)$ Bulk T cells were stimulated with uninfected or influenza infected, partially purified dendritic cells (T:APC ratio of 5:1) for $7 \mathrm{~d}$ in the presence of various cytokines. CTL responses were tested on syngeneic influenza-infected macrophages. Note the high background with IL-15. $(B)$ Bulk T cells were stimulated with purified dendritic cells at a T:DC ratio of 60:1. After $7 \mathrm{~d}$ effector cells were tested for virus specific CTL activity. Lysis of uninfected targets was $<5 \%$ at all E:T ratios used (data not shown).

sponses, and which normally counteracts the effects of IL-12, also enhanced the CTL responses significantly. IL-15 increased the CTL response as well, but also caused a substantial rise in the background (Fig. 6, hatched bars), as noted previously in the T cell proliferation assays (Fig. 2). IL-2 was similar to IL-15 in inducing backgrounds and combinations of IL-2 and IL-12 were not synergistic in enhancing CTL responses (data not shown).

\section{Discussion}

Activation of antiviral CD8+ CTLs by dendritic cells is enhanced by $I L-12$. Dendritic cells are specialized antigen-presenting cells for the induction of $\mathrm{T}$ cell-mediated immune responses (reviewed in [22]). Their efficacy is based on their ability to prime CD4+ and CD8+ T cells in small numbers and high ex- 
pression of adhesins, costimulators, and intracellular vesicles critical for antigen presentation. Another means by which dendritic cells induce potent T cell responses is via the release of IL-12. Using murine TCR transgenic CD4+ T cells, Macatonia et al. (15) showed that dendritic cells induce the differentiation of naive $\mathrm{T}$ cells into IFN $\gamma$ producing Th1 cells by synthesizing IL-12.

Dendritic cells induce potent human antiviral CD8+ CTL responses without the requirement for CD4+ T cells or exogenous cytokines (13). We hypothesized, therefore, that dendritic cells produce IL-12 when stimulating strong antiviral CD8+ CTL responses. However, dendritic cells did not produce significant levels of IL-12 after influenza virus infection or when stimulating either bulk or purified CD8+ T cells. Several stimuli known to produce IL-12 from human macrophages, e.g., LPS, Staphylococcal aureus Cowan strain 1, allogeneic $\mathrm{T}$ cells, in our hands induced little to no IL-12 when added to human blood dendritic cells. IL-12 may only be mobilized by dendritic cells after certain conditions of $T$ cell activation (15). For example, interaction between CD40L on activated T cells and CD40 on APCs is critical for the priming of Th1 cells $(23,24)$. The CD8+ CTLs generated in our system may express only low levels of CD40L. Alternatively, the production of IL-12 may critically depend on the source and/or the maturational state of dendritic cells.

The addition of low doses of IL-12 to purified bulk or $\mathrm{CD} 8+\mathrm{T}$ cells and influenza virus-infected dendritic cells increased both the proliferative and CTL activities substantially (2-20-fold). Our study provides the first evidence of the enhancing effects of IL-12 on human antiviral CD8+ T cell responses. In those instances where donors had weak or poor baseline antiviral responses, the effect of adding IL-12 was dramatic. A strong antiviral immune response was elicited where little to none could be previously detected (Figs. 3 and 6). We feel this is an amplification of a low level of CD8+ T cell memory rather than a primary response, since one would not expect to detect levels of $30-40 \%$ CTL lysis in a primary response. While enhancement to such levels are seen with IL-12 in CTL responses to alloantigens or after stimulation with anti-CD3, there the number of responsive $\mathrm{T}$ cells is very high $(9,10,12,25)$. IL-12 was also effective when the dose of dendritic cells was less than optimal or limiting (Fig. 3).

IL-12 directly amplifies the antiviral effects of highly purified CD8 $+\mathrm{T}$ cells. The amplification of both the proliferative and the antiviral CTL responses correlated with the amount of IFN $\gamma$ produced in the cultures. In these respects, IL-12 effects on enhancing antiviral CTLs is like the effects on bulk NK cells $(5,6)$, as long as antigen is being presented by dendritic cells.

Mechanism of IL-12 in enhancing CTL responses. IL-12 likely increases CTL responses through several ways. By functioning as a growth factor (7), it increases the number of T cells responding to antigen (up to twofold as shown here and reported in reference 12), and enhances the production of IL-2 $(19,26)$ and/or the expression of the IL-2 high affinity receptor (CD25, [27]). The effect of IL-12 may be direct since it is not blocked by anti-IL-2R $\alpha(7,10-12)$. Activation of NK cells by IL-12 is similarly not dependent on cytokines such as IL-2 (1, $5,6)$. In our system IL-2 was critical, since the addition of antiIL-2R $\alpha$ antibody substantially blocked CTL responses as described by others (9).

IL-12 may also upregulate the expression of perforin (11), serine esterase levels and cytotoxic granules in CD8+ CTLs $(10,12)$. A direct increase in the the CTL precursor frequency has also been postulated. However, we were unable to measure enhanced CTLp levels under limiting dilution conditions (data not shown).

IL-12-induced IFN $\gamma$ could directly enhance antiviral responses through its effects on infected target cells. This is one mechanism by which NK cells clear virus (28). We found, however, that the addition of neutralizing anti-IFN $\gamma$ antibodies did not block either the induction of or killing capacity of CD8+ CTLs in the presence of IL-12. These findings are in concordance with those of Mehrortra et al. (12) who showed that the synergistic effects of IL-2 and IL-12 on CTL generation were not blocked by anti-IFN $\gamma$, and Bloom et al. (11) in the murine system where allospecific CTL generation was studied.

Our results do not rule out a role for IFN $\gamma$ in antiinfluenza responses, however, or of cytokines such as $\mathrm{TNF} \alpha$ which are also produced in response to IL-12. This is because our assays are designed to measure cytolytic activity of virus-infected target cells vs elimination of virus through other inhibitory mechanisms. IFN $\gamma$ can clear infection by affecting viral RNA synthesis and stability, replication, and induction of mediators such as nitric oxide (29). Such mechanisms, rather than direct cytolytic activity, are thought to be the primary means by which hepatitis virus and other cytopathic infections are cleared (30).

When compared to other T cell growth factors, IL-12 appeared to be the most efficient at enhancing CTL responses. IL-2 and IL-15, while partly effective, gave high background responses possibly because of effects on IL-2 R $\beta$ expressing T cells. IL-15 was tested because it can amplify dendritic celldependent $\mathrm{T}$ cell responses (31) and increases antigen-specific proliferative T cell responses (19). IL-12 and IL-15 are synergistic in augmenting NK cell CTL function and IFN $\gamma$ production (18), but were not evaluated together because of the observed background activity of IL-15. Besides inducing the development of Th2 cells from naive CD4+ T cells, IL-4 can augment CTL responses including antiinfluenza CTL responses (32), as shown here (Fig. 6). The pathway by which IL-4 enhances dendritic cell-dependent CTL responses is not known. However, IL-4 is known to prime PBMC for IL-12 production in response to LPS or S. aureus (33). It is possible that the effects of IL-4 seen here are mediated through dendritic cells that have been primed for IL-12 production. IL-7, which has been used with dendritic cells to induce CTL responses (21) was not effective in our studies.

Restricted requirements for IL-12 in antiviral responses. The regulatory influence of IL-12 on cellular immune responses is most striking in animal models of bacterial and protozoal infection (reviewed in references 1 and 2). Surprisingly, less is known about the role of IL-12 in T cell-mediated resistance to viral infections. For instance, little is known about whether IL-12 plays a role in the development of antiviral CD8+ CTLs.

In two animal models of virus infection, lactate dehydrogenase elevating virus (34) and MCM virus infections (28), either message for IL-12 or protein is detected in macrophages and splenic cells shortly after infection. However, the primary mode of virus clearance, at least in MCMV infection, appears to be via NK cells through secretion of IFN $\gamma$, rather than CD8 + T cells. This antiviral pathway is blocked with antiIL-12 antibody or enhanced with administration of low dose IL-12 (28). In contrast, CD8+ T cell expansion is unaffected by IL-12 neutralizing antibody. In other virus infections IL-12 is not readily detectable, e.g., LCMV infection, and viral clear- 
ance is primarily dependent on the activation of CD8+ CTLs. While low doses of IL-12 enhance splenic CD8+ T cell numbers in LCMV- infected mice and decrease viral replication, cytolytic activity is not increased (35). Furthermore, the administration of anti-IL-12 antibody has no demonstrable effect on late $\mathrm{T}$ cell responses (28). Thus we would predict that the ability to rapidly induce significant IL-12 levels in vivo will determine whether NK cells are major contributors to antiviral defense.

In humans, there is evidence to suggest that IL-12 has a critical function in the progression of HIV infection (26). PBMCs from patients infected with this virus are deficient in their production of IL-12, and have suboptimal Th1 immune responses (36). Addition of IL-12 to T cells in vitro, restores recall responses to antigens $(19,26)$. It is presumed, but not established, that IL-12 deficiency also affects antiviral CD8+ T cell development and function.

In the case of influenza virus, significant levels of IL-12 were not produced by either macrophages or dendritic cells after infection in vitro. IL-12 is reportedly produced in the lungs of mice as early as day 3 after infection with influenza virus, but it is not known which cells synthesize the cytokine (37). Neutralizing anti-IL-12 antibodies increase morbidity in virusinfected mice compared with uninjected animals, suggesting that the cytokine is essential for a potent antiviral immune response (28). Influenza virus infection is known to elicit IFN $\gamma$ production in infected human PBMCs (38). Perhaps CD40Lbearing helper $\mathrm{T}$ cells are major inducers of IL-12 production by dendritic cells in infected lungs. Whether IL-12 is a requisite in vivo for clearance of influenza virus in humans cannot be determined from these experiments. Optimal clearing of influenza virus after infection likely requires CD8+ CTL effector activity (39).

Applications. IL-12 may be a useful immunomodulator when used in conjunction with dendritic cells, to enhance antigen-specific class I restricted CD8+ CTL responses in viral infections and tumors. Peptide pulsed dendritic cells induce protective immune responses and also cause tumor regression of established metastases (40-42). The concomitant use of IL-12 may reduce the need for large numbers or doses of dendritic cells. Similarly, by using dendritic cells, it may be feasible to use very low doses of IL-12. Large doses of IL-12 have exhibited toxicities in both humans and in animals (43). In HIV infection, PBMC from infected patients demonstrate impaired IL-12 production (36). Immunotherapy may be most effective in later stages of the disease when CD4+ T cell counts fall and CD8+ CTL function declines. Here, IL-12 could concomitantly enhance virus-specific CTL responses as well as CD4+ helper cell responses, the latter as previously described (26).

\section{Acknowledgments}

We thank Dr. R.M. Steinman for advice and review of the manuscript, Dr. S. Wolf for recombinant human IL-12, Dr. G. Trinchieri for anti-IL-12 antibodies, and Judy Adams for graphics.

These studies were supported by grants from the National Institutes of Health (AR-39552, AR-42557 to N. Bhardwaj), and the Irma T. Hirschl and the New York Community Trusts (N. Bhardwaj).

\section{References}

1. Trinchieri, G. 1995. Interleukin-12: a proinflammatory cytokine with immunoregulatory functions that bridge innate resistance and antigen-specific adaptive immunity. Annu. Rev. Immunol. 13:251-276.
2. Trinchieri, G. 1994. Interleukin-12: a cytokine produced by antigen-presenting cells with immunoregulatory functions in the generation of T-helper cells type 1 and cytotoxic lymphocytes. Blood. 84:4008-4027.

3. Scharton, T.M., and P. Scott. 1993. Natural killer cells are a source of interferon gamma that drives differentiation of CD4+ T cell subsets and induces early resistance to Leishmania major in mice. J. Exp. Med. 178:567-577.

4. Chehimi, J., N.M. Valiante, A. D'Andrea, M. Rengaraju, Z. Rosado, M. Koyayashi, B. Perussia, S.F. Wolf, S.E. Starr, and G. Trinchieri. 1993. Enhancing effect of natural killer cell stimulatory factor (NKSF/interleukin-12) on cellmediated cytotoxicity against tumor-derived and virus-infected cells. Eur. J. Immunol. 23:1826-1830.

5. Chan, S.H., B. Perussia, J.W. Gupta, M. Kobayashi, M. Pospisil, H.A. Young, S.F. Wolf, D. Young, S.C. Clark, and G. Trinchieri. 1991. Induction of interferon $\gamma$ production by natural killer cell stimulatory factor: characterization of the responder cells and synergy with other inducers. J. Exp. Med. 173: 869-879.

6. Kobayashi, M., L. Fitz, M. Ryan, R.M. Hewick, S.C. Clark, S. Chan, R. Loudon, F. Sherman, B. Perussia, and G. Trinchieri. 1989. Identification and purification of natural killer cell stimulatory factor (NKSF), a cytokine with multiple biologic effects on human lymphocytes. J. Exp. Med. 170:827-845.

7. Gately, M.K., B.B. Desai, A.G. Wolitzky, P.M. Quinn, C.M. Dwyer, F.J. Podlaski, P.C. Familletti, F. Sinigaglia, R. Chizonnite, U. Gubler, and A.S. Stern. 1991. Regulation of human lymphocyte proliferation by a heterodimeric cytokine, IL-12 (cytotoxic lymphocyte maturation factor). J. Immunol. 147:874882 .

8. Seder, R.A., and W.E. Paul. 1994. Acquisition of lymphokine-producing phenotype by CD4+ T cells. Annu. Rev. Immunol. 12:635-673.

9. Gately, M.K., A.G. Wolitzky, P.M. Quinn, and R. Chizzonite. 1992. Regulation of human cytolytic lymphocyte responses by interleukin-12. Cell. Immunol. 143:127-142.

10. Chouaib, S., J. Chehimi, L. Bani, N. Genetet, T. Tursz, F. Gay, G. Trinchieri, and F. Mami-Chouaib. 1994. Interleukin 12 induces the differentiation of major histocompatibility complex class I-primed cytotoxic T-lymphocyte precurosrs into allospecific cytotoxic effectors. Proc. Natl. Acad. Sci. USA. 91: 12659-12663.

11. Bloom, E.T., and J.A. Horvath. 1994. Cellular and molecular mechanisms of the IL-12-induced increase in allospecific murine cytolytic T cell activity. Implications for the age-related decline in CTL. J. Immunol. 152:4242-4254.

12. Mehrotra, P.T., D. Wu, J.A. Crim, H.S. Mostowski, and J.P. Siegel. 1993. Effects of IL-12 on the generation of cytotoxic activity in human CD8+ T lymphocytes. J. Immunol. 151:2444-2452.

13. Bhardwaj, N., A. Bender, N. Gonzalez, L.K. Bui, M.C. Garrett, and R.M. Steinman. 1994. Influenza virus-infected dendritic cells stimulate strong proliferative and cytolytic responses from human CD8+ T cells. J. Clin. Invest. 94:797-807.

14. Bender, A., L.K. Bui, M.A.V. Feldman, M. Larsson, and N. Bhardwaj. 1995. Inactivated influenza virus, when presented on dendritic cells, elicits human CD8 ${ }^{+}$cytolytic T cell responses. J. Exp. Med. 182:1663-1671.

15. Macatonia, S.E., N.A. Hosken, M. Litton, P. Vieira, C. Hsieh, J.A. Culpepper, M. Wysocka, G. Trinchieri, K.M. Murphy, and A. O'Garra. 1995. Dendritic cells produce IL-12 and direct the development of Th1 cells from naive CD4+ T cells. J. Immunol. 154:5071-5079.

16. Kang, K.F., M. Kubin, K.D. Cooper, S.R. Lessin, G. Trinchieri, and A.H. Rook. 1996. IL-12 synthesis by human Langerhans cells. J. Immunol. 156: 1402.

17. Kanangat, S., S. Nair, J.S. Babu, and B.T. Rouse. 1995. Expression of cytokine mRNA in murine splenic dendritic cells and better induction of $\mathrm{T}$ cellderived cytokines by dendritic cells than by macrophages during in vitro costimulation assay using specific antigens. J. Leukocyte Biol. 57:310-316.

18. Carson, W.E., J.G. Giri, M.J. Lindemann, M.L. Linett, M. Ahdieh, R. Paxton, D. Anderson, J. Eisenmann, K. Grabstein, and M.A. Caligiuri. 1994. Interleukin (IL) 15 is a novel cytokine that activates human natural killer cells via components of the IL-2 receptor. J. Exp. Med. 180:1395-1403.

19. Seder, R.A., K.H. Grabstein, J.A. Berzofsky, and J.F. McDyer. 1995. Cytokine interactions in human immunodeficiency virus-infected individuals: roles of interleukin IL-2, IL-12, and IL-15. J. Exp. Med. 182:1067-1078.

20. Fesq, H., M. Bacher, M. Nain, and D. Gemsa. 1994. Programmed cell death (apoptosis) in human monocytes infected by influenza virus. Immunobiology 190:175-182.

21. Celis, E., V. Tsai, C. Crimi, R. DeMars, P.A. Wentworth, R.W. Chestnut, H.M. Grey, A. Sette, and H.M. Serra. 1994. Induction of anti-tumor cytotoxic $\mathrm{T}$ lymphocytes in normal humans using primary cultures and synthetic peptide epitopes. Proc. Natl. Acad. Sci. USA. 91:2105-2109.

22. Steinman, R.M. 1991. The dendritic cell system and its role in immunogenicity. Annu. Rev. Immunol. 9:271-296.

23. Shu, D., M. Kiniwa, C.Y. Wu, C. Maliszewski, N. Vezzio, J. Hakimi, M. Gately, and G. Delespesse. 1995. Activated T cells induce interleukin-12 production by monocytes via CD40-CD40 ligand interaction. Eur. J. Immunol. 25: $1125-1128$.

24. Stuber, E., W. Strober, and M. Neurath. 1996. Blocking the CD40LCD40 interaction in vivo specifically prevents the priming of T helper 1 cells through the inhibition of interleukin 12 secretion. J. Exp. Med. 183:693-698. 
25. Young, J.W., and R.M. Steinman. 1990. Dendritic cells stimulate primary human cytolytic lymphocyte responses in the absence of $\mathrm{CD} 4^{+}$helper $\mathrm{T}$ cells. J. Exp. Med. 171:1315-1332.

26. Clerici, M., D.R. Lucey, J.A. Berzoksky, L.A. Pinto, T.A. Wynn, S.P. Blatt, M.J. Dolan, C.W. Hendrix, S.F. Wolf, and G.M. Shearer. 1993. Restoration of HIV-specific cell-mediated immune responses by interleukin-12 in vitro. Science (Wash. DC). 262:1721-1724.

27. Robertson, M.J., R.J. Soiffer, S.F. Wolf, T.J. Manley, C. Donahue, D. Young, S.H. Herrmann, and J. Ritz. 1992. Response of human natural killer (NK) cells to NK cell stimulatory factor (NKSF): cytolytic activity and proliferation of NK cells are differentially regulated by NKSF. J. Exp. Med. 175:779788 .

28. Orange, J.S., and C.A. Biron. 1996. An absolute and restricted requirement for IL-12 in natural killer cell IFN-gamma production and antiviral defense. J. Immunol. 156:1138-1142.

29. Muller, U., U. Steinhoff, L.F.L. Reis, S. Hemmi, J. Pavlovic, R.M. Zinkernagel, and M. Aguet. 1994. Functional role of type I and type II interferons in antiviral defense. Science (Wash. DC). 264:1918-1921.

30. Guidotti, L.G., T. Ishikawa, M.V. Hobbs, B. Matzke, R. Schreiber, and F.V. Chisari. 1996. Intracellular inactivation of the hepatitis B virus by cytotoxic T lymphocytes. Immunology. 4:25-36.

31. Jonuleit, H., U. Kuhn, G. Muller, M. Wolfl, S. Lohmann, J. Saloga, D. Becker, J. Knop, and A.H. Enk. 1995. Keratinocyte-derived IL-15 enhances accessory functions of epidermal LC and blood dendritic cells. J. Invest. Dermatol. 105:861 (Abstr.)

32. Horohov, D.W., J.A. Crim, P.L. Smith, and J.P. Siegel. 1988. IL-4 (B cell-stimulatory factor 1) regulates multiple aspects of influenza virus-specific cell-mediated immunity. J. Immunol. 141:4217-4224.

33. D'Andrea, A., X. Ma, M. Aste-Amezaga, C. Paganin, and G. Trinchieri. 1995. Stimulatory and inhibitory effects of IL-4 and IL-13 on the production of cytokines by human peripheral blood mononuclear cells: priming for IL-12 and tumor necrosis factor alpha production. J. Exp. Med. 181:537-546.
34. Coutelier, J.-P., J. Van Broeck, and S.F. Wolf. 1995. Interleukin-12 gene expression after viral infection in the mouse. J. Virol. 69:1955-1958.

35. Orange, J.S., S.F. Wolf, and C.A. Biron. 1994. Effects of IL-12 on the response and susceptibility to experimental viral infections. J. Immunol. 152:1253.

36. Chehimi, J., S.E. Starr, I. Frank, A. D'Andrea, X. Ma, R.R. Macgregor, J. Sennelier, and G. Trinchieri. 1994. Impaired interleukin-12 production in human immunodeficiency virus-infected patients. J. Exp. Med. 179:1361-1366.

37. Monteiro, J.M., and G. Trinchieri. 1995. Role of IL-12 in the in vivo immune response to influenza infection. In Interleukin 12: Cellular and Molecular Immunology of an Important Regulatory Cytokine, New York Acad. Sci. Conf. P24. (Abstr.)

38. Yamada, Y.K., A. Meager, A. Yamada, and F.A. Ennis. 1986. Human interferon alpha and gamma production by lymphocytes during the generation of influenza virus-specific cytotoxic T lymphocytes. J. Gen. Virol. 67:2325-2334

39. McMichael, A. 1994. Cytotoxic T lymphocytes specific for influenza virus. Curr. Top. Microbiol. Immunol. 189:75-91.

40. Paglia, P., C. Chiodoni, M. Rodolfo, and M.P. Colombo. 1996. Murine dendritic cells loaded in vitro with soluble protein prime CTL against tumor antigen in vivo. J. Exp. Med. 183:317-322.

41. Mayordomo, J.I., T. Zorina, W.J. Storkus, L. Zitvogel, C. Celluzzi, L.D Falo, C.J. Melief, S.T. Ilstad, W.M. Kast, A.B. DeLeo, and M.T. Lotze. 1995. Bone marrow-derived dendritic cells pulsed with synthetic tumour peptides elicit protective and therapeutic antitumour immunity. Nature Med. 1:12971302.

42. Celluzzi, C.M., J.I. Mayordomo, W.J. Storkus, M.T. Lotze, and L.D. Falo, Jr. 1996. Peptide-pulsed dendritic cells induce antigen-specific, CTLmediated protective tumor immunity. J. Exp. Med. 183:283-287.

43. Orange, J.S., T.P. Salazar-Mather, S.M. Opal, R.L. Spencer, A.H Miller, B.S. McEwen, and C.A. Biron. 1995. Mechanism of interleukin 12-mediated toxicities during experimental viral infections: role of tumor necrosis factor and glucocorticoids. J. Exp. Med. 181:901-914. 